\title{
HERPETOFAUNA AND FISH
}

\section{FISH SURVEY OF THE \\ SASKATCHEWAN PORTION OF THE MISSOURI RIVER BASIN}

BRUCE R. MCCULLOCH, Department of Zoology, University of Manitoba, Winnipeg Manitoba R3T 2N2, JAMES R. DUNCAN, Manitoba Conservation Data Centre, 200 Saulteaux Cr, Winnipeg, Manitoba, R3J 3W3 and R. JEFFREY KEITH, Saskatchewan Conservation Data Centre, 3211 Albert Street, Regina, Saskatchewan S4S 5W6

\section{Introduction}

The purpose of this survey was to document the occurrence of rare and threatened fish species in the Saskatchewan portion of the upper Missouri River drainage. While much focus has been placed on species of commercial and economic importance, this survey sought information on the distribution of game and non-game fish. Many groups, such as cyprinids ("minnows"), play an important role in the food web of an aquatic ecosystem. As many cyprinids are associated with unique microhabitats, and segregate accordingly ${ }^{10}$, they serve as good indicator species for the overall health of a river, and reflect the ecosystem's ability to sustain a level of biological diversity. Other species such as the mountain sucker (Catostomus platyrhynchus) are also associated with specific habitats, and their population trends closely reflect habitat perturbations. $^{5}$

\section{Methods and Materials}

Fish were sampled throughout southwestern Saskatchewan from June 19 - 30, 1993 in permanent creeks and rivers of the upper Missouri River drainage. Water from these sources eventually flows into the Gulf of Mexico
(Fig 1). Individual site selection was based mainly on accessibility. Latitude and longitude of each site was recorded using a Trimble Flightmate Global Positioning System (Model 20285-00 Rev B, Trimble Navigation Ltd.) device which is accurate to \pm 100 metres on a two dimensional plane. At 11 sites, deeper and more homogeneous stretches of water were sampled by hauling a seven-metre small-mesh (3 $\mathrm{mm}$ bar) seine (Table 1). Wherever possible, the haul covered the entire stream width for a distance of least 20 metres. At this point, the wings of the seine were dragged up on shore, leaving the bag containing the fish in the water. Fish were then transferred to a bucket containing adequate water for respiration. For shallow, fast stretches, a Coffelt gas-powered electro-fisher was operated between 100 and 300 volts, depending on stream conductivity. Fish were dip-netted as encountered and revived in a 10 litre plastic pail with adequate water for respiration. Once the sampling procedure was completed, all fish were identified to species. Wherever possible, fish were released in the same micro-habitat from which they were removed. Any specimen which could not be confidently identified on site was anaesthetized in 2-phenoxyethanol prior 


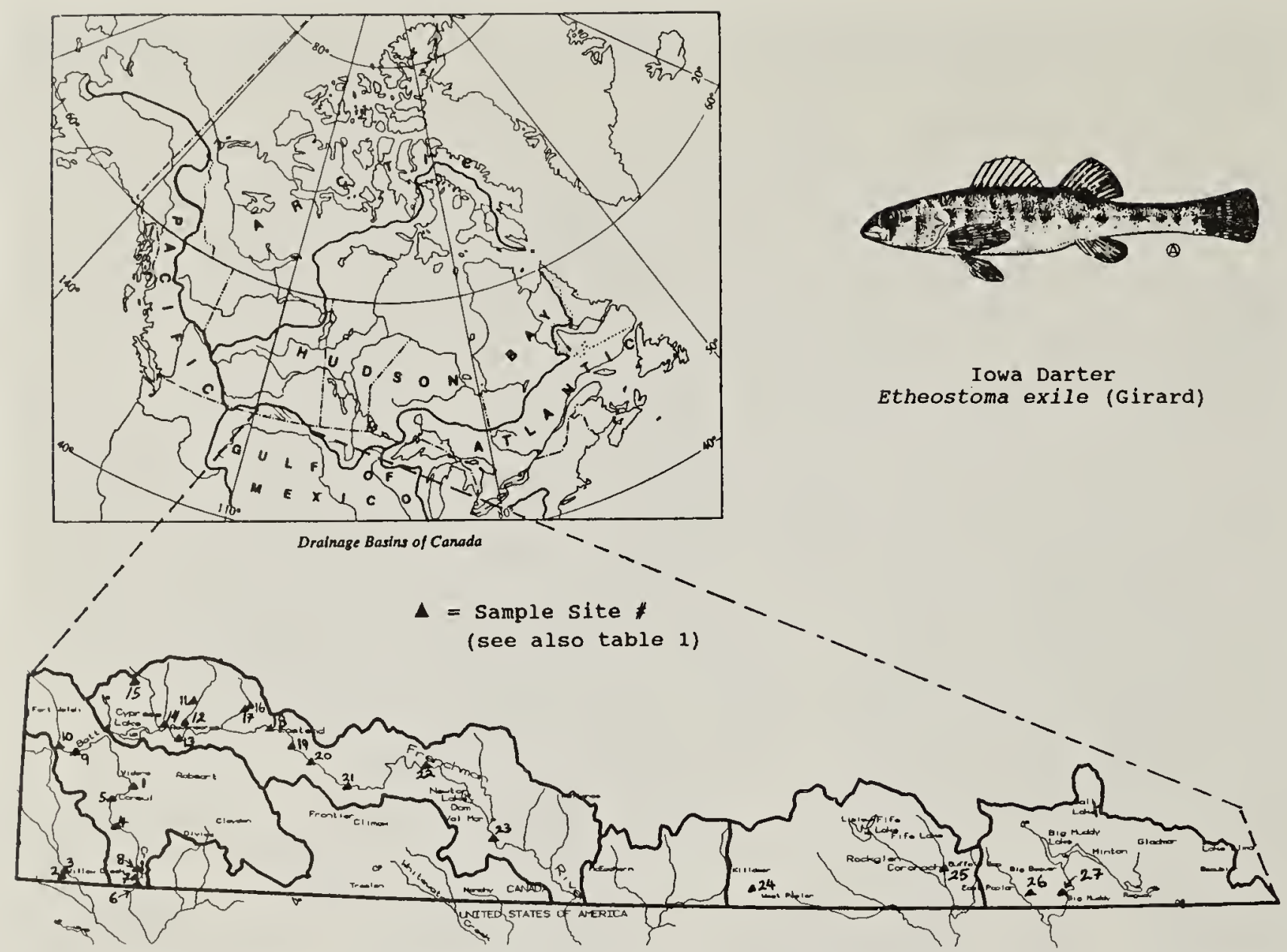

Figure 1. Fish Survey of the Saskatchewan partion of the Missouri River Basin.

to fixation in $10 \%$ formaldehyde. Subsequent identification was accomplished in the laboratory using appropriate characteristics. At each site, water temperature was recorded using a Hach digital thermometer, while stream width and depth was measured with a metre stick. Substrate type also was noted, with all information recorded in a field book.

\section{Results and Discussion}

Twenty-seven sites were sampled (Table 1, Fig 1): Three of these were sampled twice for a total of 30 samples. Twenty of the 26 expected species in the drainage were collected (Table 2). Of the 26 expected species, five are exotic or introduced species. Seventeen of the 21 native or endemic species were collected.

The collections made in Caton and Morgan creeks represent the first published surveys conducted on these waters (Ron Jensen, pers. comm.) New localities were also recorded for the
Finescale Dace (Phoxinus neogeaus) and Mountain Sucker. A total of five specimens were sacrificed. Two mountain suckers and one Lake Chub (Couesius plumbeus) were taken to add to museum collections, while two Brassy Minnows (Hybognathus hankinsoni) were taken for definitive identification, since species within the genus Hybognathus are similar and difficult to identify in the field. ${ }^{11}$

The Fathead Minnow (Pimephales promelas), White Sucker (Catostomus commersoni), and Brook Stickleback (Culaea inconstans) were the most common species collected in slow, deeper water, while the Longnose Dace (Rhinichthys cataractae) was common in riffle-type habitat. The Northern Redbelly Dace (Phoxinus eos) was collected in good numbers from a range of habitats. All of the above species are considered common in Saskatchewan, and it comes as no surprise that they were found to be widespread (Table 2) and to occur in large numbers (Fig 2). 
These five species represented almost 88 percent of the total number of fish sampled.

Of particular interest are the species considered rare in this drainage within Saskatchewan. Single individuals of the brassy minnow and the lake chub were collected at only four and three sites, respectively (Table 2 ). While the lake chub is more common in lakes and other large water bodies in other parts of its range ${ }^{12}$, Wells stated that creeks and rivers are preferred in the Missouri basin.16 The relative absence of the brassy minnow is also noteworthy. Scott and Crossman state that while the brassy minnow occupies creeks in eastern Canada, it is more common in bog ponds with dark, stained water. ${ }^{12}$ The single Battle Creek specimen was taken in an area of dense vegetation. This habitat is favourable to the species as it feeds mainly on plant material which it is able to break down in its long, coiled digestive tract. ${ }^{3,11}$
One Burbot (Lota lota) was collected in the same area of the Frenchman River as those specimens taken by Bevan in 1978; the distribution of this species appears to be restricted to this portion of the watershed. ${ }^{1}$ The single Stonecat (Noturus flavus), also collected in the Frenchman River at Eastend, represents a successfully invading species. First recorded in the Frenchman River in 1970, it expanded its range upstream in this river, and by 1982 it was present in Conglomerate Creek. ${ }^{1}$ A similar invasion by the stonecat has occurred in Manitoba. Since its 1969 discovery in the Red River near Winnipeg ${ }^{13}$, it has been reported in the Assiniboine River westward to the town of Shellmouth, as well as in the Souris and Little Saskatchewan rivers. ${ }^{14}$ While absent from the Qu'Appelle River in Saskatchewan, its appearance in the Assiniboine River upstream from the mouth of the Qu'Appelle would suggest occupation of the latter in the future.

In general, sampling efficiency and

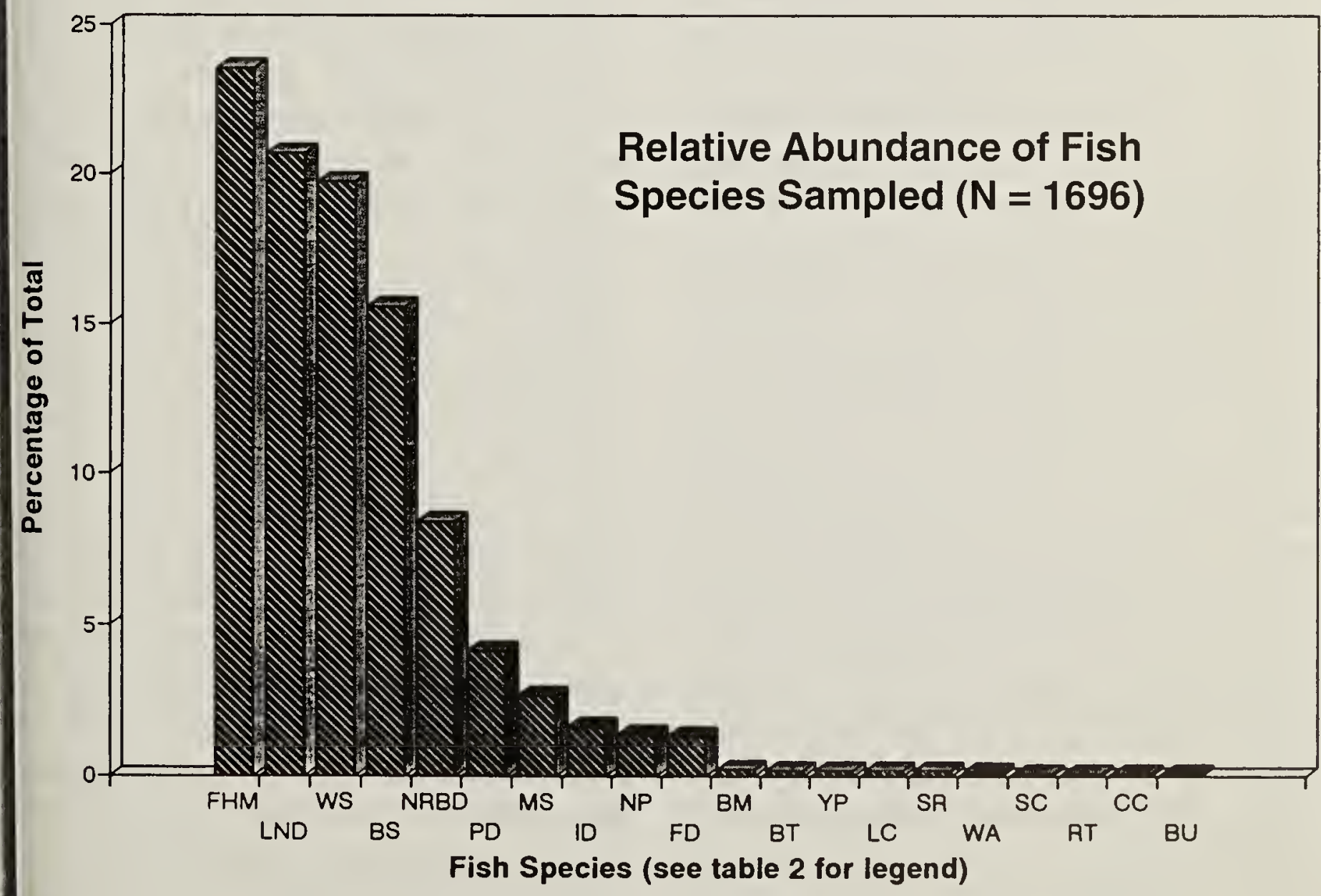

Figure 2. Relative Abundance of Fish. Species Samples $(N=1696)$ 
season affect the numbers of all species. The rarity of both the Stonecat and Burbot in our collections may be due to sampling procedure. Both species are nocturnal ${ }^{9}$ and seek shelter during the day under the cover of rocks and logs. While electrofishing effectively immobilizes these fish, both species (especially stonecats) may become wedged under rocks. Due to time constraints, only a few chosen rocks were lifted to check for wedged individuals. Nocturnal sampling may increase the yield of these two species in Missouri headwaters, thereby increasing our knowledge of their contribution to stream integrity in Saskatchewan.

Another species of interest is the Mountain Sucker, one of eight small catostomids restricted to western North America. ${ }^{4}$ The Saskatchewan distribution of the mountain sucker includes the South Saskatchewan River and the Milk River drainage (Battle Creek and Frenchman River tributaries), but is restricted to regions of increased elevation. ${ }^{4}$ In streams, mountain suckers inhabit areas of moderate current with rocky substrate. ${ }^{8}$ In a 100 metre stretch of Caton Creek, mountain suckers and Longnose Dace were collected exclusively in the shallow, rocky riffle areas, while White Suckers, Pearl Dace (Margariscus margarita), Northern Redbelly Dace, and Fathead Minnows were dominant in the pools which alternated with the riffles. The two Mountain Suckers taken in a seine haul of the deep pool upstream of the electrofished stretch of the creek probably were occupying the area immediately below a culvert, where a noticeable current was present. The three Mountain Suckers from Conglomerate Creek were also taken from a narrow, rocky stretch with high water velocity.
Curiously, no Mountain Suckers were collected from Sucker Creek, even though suitable habitat is plentiful. This absence of suckers may be due to the naturally-reproducing population of Brook Trout (Salvelinus fontinalis) inhabiting the creek. With a maximum size of approaching only $175 \mathrm{~mm}$ (Standard Length) $^{4}$, the suckers are vulnerable to trout predation for a good portion of their lives. ${ }^{12}$ Glover found that stream rehabilitation in South Dakota, while effective in increasing Brown Trout (Salmo trutta) populations, was detrimental to Mountain Sucker populations, reducing them as much as 90 percent. ${ }^{6}$ Decker also found that Mountain Suckers become extremely rare where reservoir construction results in habitat loss due to reduced velocity and increased depth. ${ }^{5}$ Similar population declines have been observed for stonecats in areas altered to form reservoir-like conditions. ${ }^{15}$ Unfortunately, no data regarding species composition in Sucker Creek were available prior to initiation of trout stocking.

While some species which occur in the Saskatchewan portion of the drainage were not collected, their absence can be attributed to restricted distribution and habitat preference or sampling bias. For example, only one locality for the Flathead Chub (Platygobio gracilis) has been reported. ${ }^{1}$ Its occurrence in the Frenchman River is in accordance with its preference for fluctuating streams with turbid and alkaline water. ${ }^{2}$ Collections made by the senior author in Manitoba suggest that Flathead Chubs also prefer relatively fast-flowing sections of medium to large rivers, where they occupy mid-channel gravel habitat. The Assiniboine River, where it flows through the Manitoba escarpment, is one such location. It is of special note that in Montana, flatheac chubs are collected in association with many species considered rare in 
Saskatchewan, such as the Mountain Sucker, the Stonecat, and the Western Silvery Minnow (Hybognathus argyritis $).^{7}$

As for the Western Silvery Minnow, its occurrence in Saskatchewan is, at best, extremely limited, if realized at all. This species has been reported from only three localities. Of these, specimens from two of the localities were re-identified as the Mississippi Silvery Minnow (Hybognathus nuchalis) and recorded as such by Atton and Merkowsky. ${ }^{1}$ However, Page and Burr consider the Hybognathus species occurring in the upper Missouri River to be $H$. argyritis, while $H$. nuchalis is restricted to lowland areas of the Mississippi River north to Minnesota. ${ }^{11}$ Both species prefer sluggish backwater areas. It is possible that positive identifications of the Saskatchewan specimens may be achieved only after examination of the basioccipital process. ${ }^{11}$

Absence of the Goldeye (Hiodon alosoides) from our collections is due both to its limited distribution (found only in the East Poplar River) and exclusion of habitat preference from our sampling procedures. The Goldeye is associated with medium to large turbid lowland rivers and lakes ${ }^{12}$ where it is commercially harvested. Its added preference for impoundments ${ }^{11}$ may result in population increases, given the presence of several dams in the Poplar River system.

Thus, our data suggest that possible threats to rare non-game fish species nclude habitat alteration, either from hatural (e.g., beaver dams) or manmade sources and species ntroductions. The collection from the oplar River upstream of the dams vielded a low species diversity (Fathead Minnows and Brook Sticklebacks tominated the sample) and included the only appearance of the Common Carp (Cyprinus carpio), a species regrettably introduced into North America from Europe. Impact assessments of future human-induced habitat alterations, including species introductions, should consider the consequences to native non-game fish populations.

\section{Acknowledgements}

This survey was funded by the Saskatchewan Natural History Society, the Regina Natural History Society, and the Saskatchewan Conservation Data Centre. We gratefully acknowledge Roger Baldwin, Maynard Chen, Ross Evans, Alvin Frey, Natalie Giraudier, Gavin Hanke, Roy Jennett, Ron Jensen, Sylvie Laframboise, P. Luchinski, Kurt Mazer, Florence Miller, Richard Moorhead, Al Murray, Dan McGill, Keith Roney, Curt Schroeder, Vicki Sahanatien, Ken Stewart, Merv Swanson and the Royal Saskatchewan Museum for assistance in preparing for this survey. The following groups, and their employees, facilitated the survey by providing the necessary permits and/ or equipment; Fisheries Branch, Grasslands National Park, Prairie Farm Rehabilitation Administration, and Saskatchewan Environment and Resource Management. Access to sampling sites on private land was kindly permitted by Ross \& Heather Beierbach, Bill Caton \& Sherry Wright, George Hayes, and Willard \& Mabel Nelson. Jim Gerhart, Saskatchewan Water Corporation, provided a base map of the Saskatchewan portion of the Missouri River basin used in Figure 1. Fish specimens collected were identified with the assistance of the Stewart-Hay Museum fish collection, University of Manitoba, Winnipeg, Manitoba. Early drafts of the manuscript were kindly reviewed by Gavin Hanke, Wayne Harris, Dale Hjertaas, Ron Jensen, Walter Lysack, Robert Nero, Keith Roney, and Curt Schroeder. 
Literature Cited

1.ATTON, F.M. and J.J. MERKOWSKY. 1983. Atlas of Saskatchewan fish. Department of Parks and Renewable Resources. Technical Report 83-2. $281 \mathrm{pp}$.

2.BROWN, C.J.D. 1971. Fishes of Montana. Big Sky Books. Montana State Univ., Bozeman, Montana. 207pp.

3.BURR, B.M. 1978. Hybognathus hankinsoni Hubbs. Brassy minnow. pp. 175 IN: D.S. Lee, et al. Atlas of North American freshwater fishes. Publication \# 1980-12, North Carolina State Museum of Natural History, Raleigh: 854 pp.

\section{CAMPBELL, R.E. 1992. Status of the} mountain sucker, Catostomus platyrhynchus, in Canada. Can. FieldNat. 106:27-35.

5.DECKER, L.M. 1989. Coexistence of two species of sucker, Catostomus, in Sagehen Creek, California, and notes on their status in the western Lahontan basin. Great Basin Nat. 49:540-551.

6.GLOVER, R.D. 1986. Trout stream rehabilitation in the Black Hills of South Dakota. Trout Stream Habitat Improvement Workshop 5:7-15.

7.GOULD, W. 1985. Aspects of the biology of the flathead chub (Hybopsis gracilis) in Montana. Great Basin Nat. 45:332-336.

8. HAUSER, W.J. 1969. Life history of the mountain sucker, Catostomus platyrhynchus, in Montana. Trans. Amer. Fish. Soc. 98:209-215.

9.MCCULLOCH, B.R. and K.W. STEWART. 1992. Habitat and diet comparisons between spatial interactions between longnose dace (Rhinichthys cataractae) and stonecat (Noturus flavus) in the Little
Saskatchewan River: Interactions between a native and invading species. pp 75-91 IN: 1992 Interbasin Biota Transfer Study Program Proceedings. North Dakota Water Resources Research Institute. 150pp.

10.MENDELSON, J. 1975. Feeding relationships among species of Notropis (Pisces: Cyprinidae) in a Wisconsin stream. Ecological Monogr. 45:199-230.

11.PAGE, L.M. and B.M. BURR. 1991. A field guide to the freshwater fishes. Houghton Mifflin Company, Boston. 432pp.

12.SCOTT, W.B. and E.J. CROSSMAN. 1973. Freshwater fishes of Canada. Fish. Res. Board of Canada. Bull. \#184. $966 \mathrm{pp}$.

13.STEWART, K.W. and C.C. LINDSEY. 1970. First specimens of the stonecat, Noturus flavus, from the Hudson Bay drainage. Journal of the Fisheries Research Board of Canada. 27:170-172.

14.STEWART, K.W. and B.R. MCCULLOCH. 1990. The stonecat, Noturus flavus, in the Red RiverAssiniboine River watershed: Progress report on a study of an invading species. pp 69-85 IN: 1990 Interbasin Biota Transfer Study Program Proceedings, North Dakota Water Resources Research Institute. 144 pp.

15.TAYLOR, W.R. 1969. A revision of the catfish genus Noturus Rafinesque with an analysis of higher groups in the ictaluridae. U.S. Nat. Mus. Bull. \#282. $315 p p$.

16.WELLS, A.W. 1978. Couesius plumbeus (Agassiz). Lake chub. pp. 150 IN: D.S. Lee, et al . Atlas of North American freshwater fishes. Publication \# 1980-12, North Carolina State Museum of Natural History, Raleigh. 854 pp. 


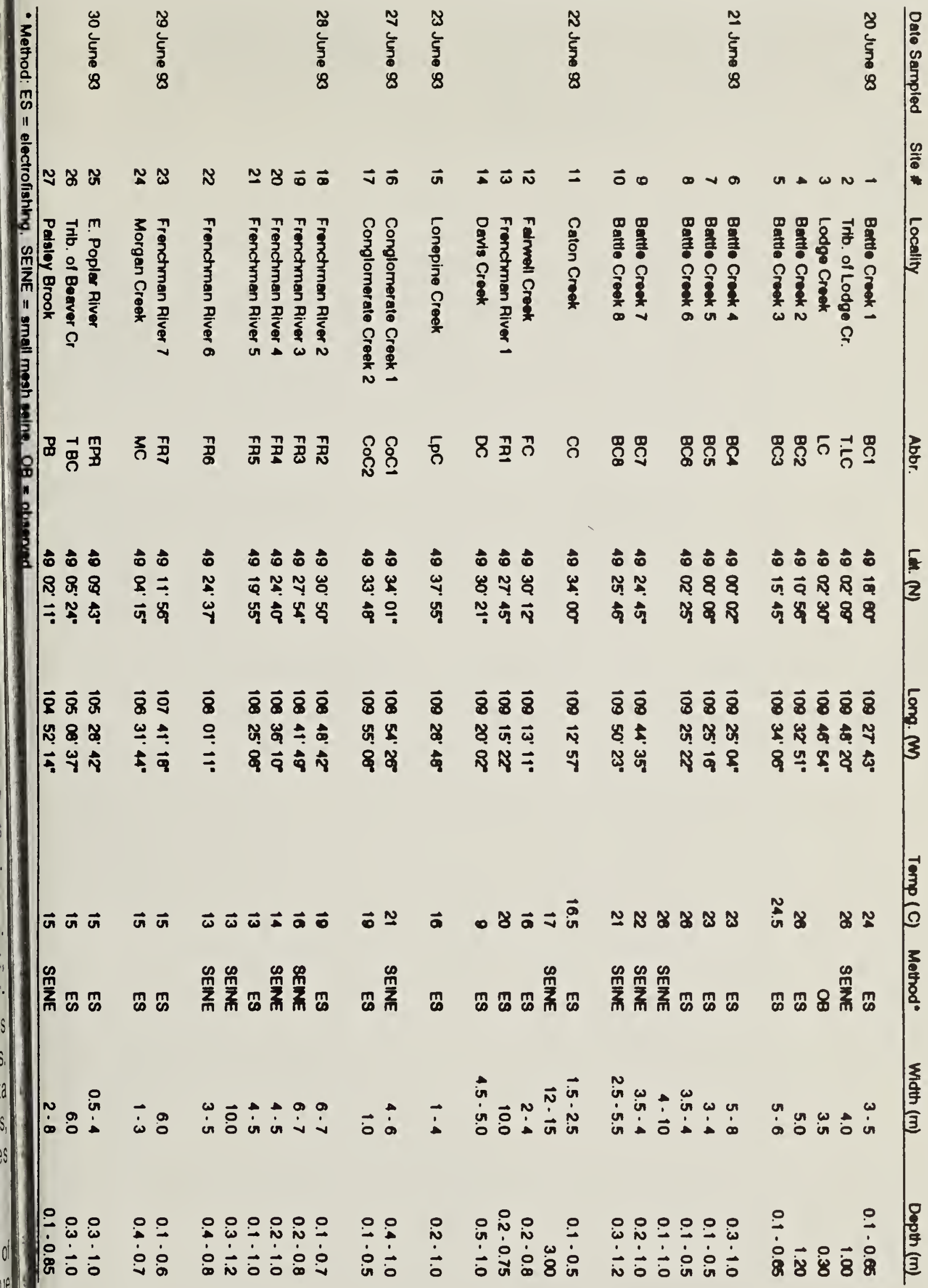




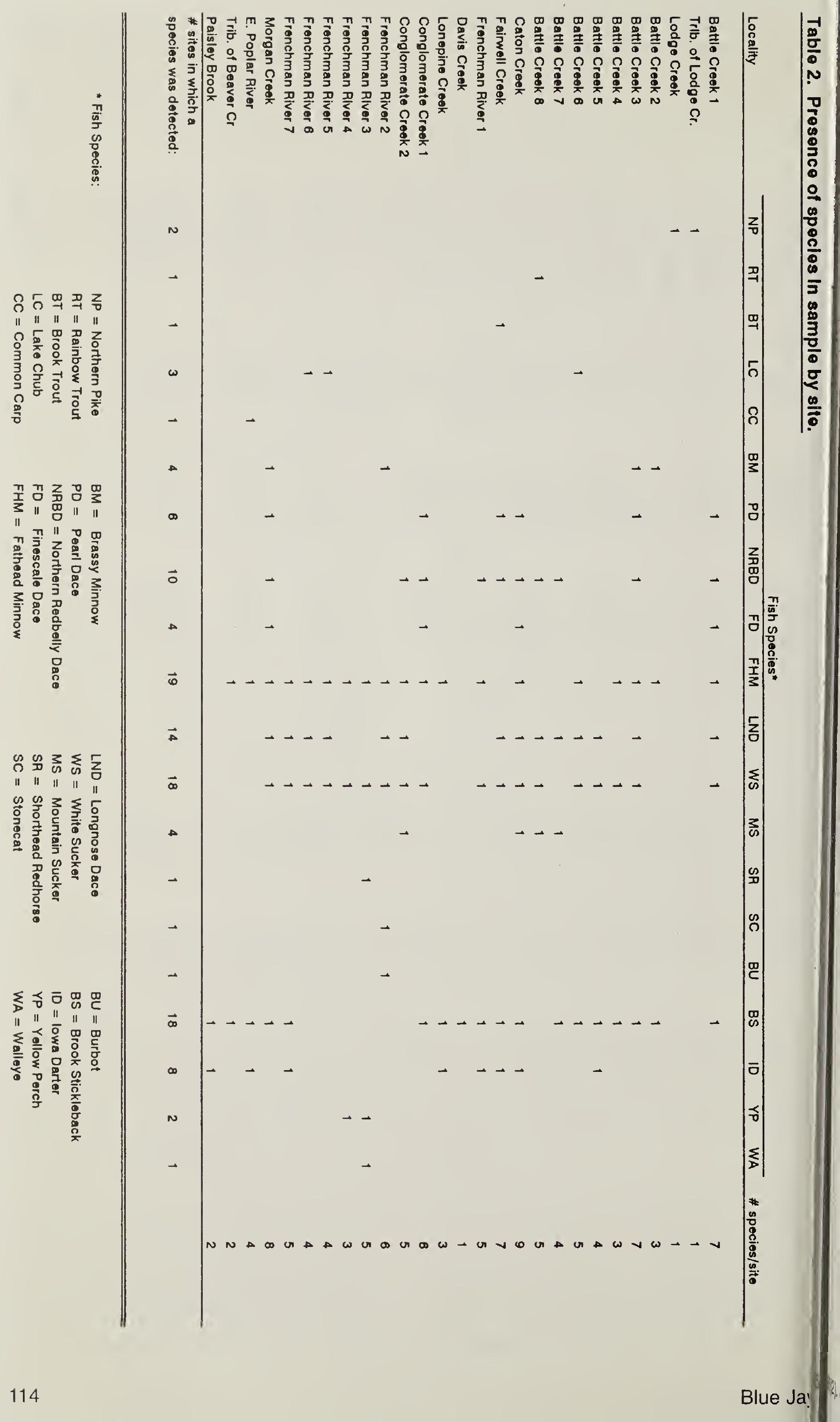




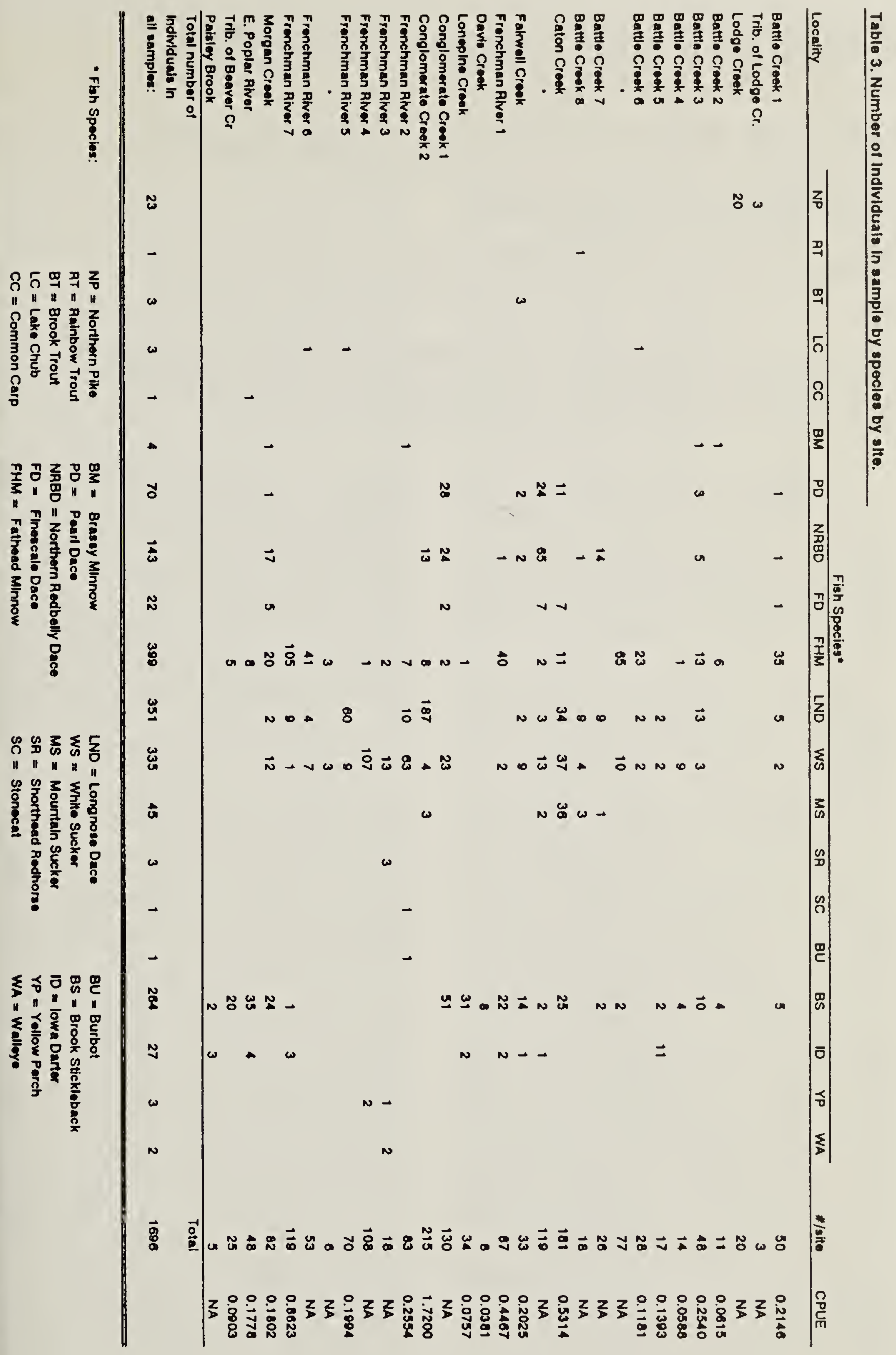

